\title{
Haemodynamic Responses to Insertion of Proseal Laryngeal Mask Airway with Sodium Thiopentone Preceded by Topical Lignocaine: A Comparison with Propofol alone
}

\author{
Mohammad Sadiq Malla, M.D., Samina Ashraf Kirmani, M.D., Showkat Ahmad Gurcoo, M.D., \\ Ifitikhar Bakshi, M.S., Mushtaq A Laway, M.S. \\ Department of Anaesthesiology \& Critical Care, Sher-i-Kashmir Institute of Medical Sciences, Srinagar
}

\section{A B S T R A C T}

BACKGROUND: Propofol is the most common inducing agent for Laryngeal Mask Airway insertion but it causes haemodynamic instability.

OBJECTIVE: To assess haemodynamic responses to insertion of Proseal Laryngeal Mask Airway (pLMA) with sodium thiopentone administration preceded by topical lignocaine and comparing with Propofol.

METHODS: 100 patients of either sex in the age range of 16-60 years belonging to ASAl/II scheduled for open cholycystectomy were selected and allocated into one of the two groups. Group I (Propofol group) received Propofol $2.5 \mathrm{mg} / \mathrm{kg}$ while as Group II (Thiopentone group) received topical lignocaine and intravenous sodium thiopentone for pLMA insertion. All patients received fentanyl $1 \mu \mathrm{g} / \mathrm{kg}$ intravenously 3 minutes before induction. Haemodynamic parameters like pulse rate, mean systolic and diastolic blood pressures between the two groups were compared.

RESULTS: The decrease in pulse rate, systolic and diastolic pressures in propofol group was more as compared to topical lignocaine and sodium thiopentone group while inserting pLMA. Number of attempts of pLMA insertion and oxygen saturation were same between the two groups when pLMA was inserted but the duration of apnoea was more in propofol than in topical lignocaine and sodium thiopentone group. Thus we concluded that sodium thiopentone administration preceded by topical lignocaine provided more haemodynamic stability as compared to propofol while Proseal LMA insertion. JMS 2010;13(2):56-59

Key Words: Propofol, Proseal Laryngeal MaskAirway (pLMA), Laryngospasm

Endotracheal intubation is regarded as a gold standard technique for maintaining airway but this technique needs an expert for intubation and is associated with increased pressure response and postoperative complications like sorethroat. ${ }^{1}$ Airway management has been revolutionized with new airway

Correspondence and reprint requests to:

Dr. Mohammad Sadiq Malla

Senor Resident,

Department of Anesthesiology \& Critical Care,

Sher-i-Kashmir Institute of Medical Sciences, Srinagar, Kashmir

(J\&K) India - 190011

E-Mail: dr._sadiq786@rediffmail.com devices. ${ }^{2}$ LMA is one of the new supraglotic airway devices used commonly to maintain airway. LMA is an alternative to endotracheal intubation and facemask for spontaneous as well as controlled positive pressure ventilation. ${ }^{3-5}$ Compared to facemask, it provides better seal in edentulous patients or if the patient has beard. Besides it keeps anesthesiologists hands free, so fatigue is less and remote observation is possible. ${ }^{2,6}$ LMA has become popular in airway management during elective anaesthesia and difficulty airway situation as well as emergency situation. $^{7}$

Propofol is the most commonly used inducing agent for insertion of $\mathrm{LMA}^{8}{ }^{8} \mathrm{~A}$ depolarizing muscle relaxant is not 
necessary for insertion of LMA, thus avoiding succinylcholine induced muscle pain which is particularly of benefit when early ambulation is important. ${ }^{9}$ In the setting of day care anaesthesia with its emphasis on early ambulation, newer induction agent propofol with its short elimination ${ }^{9}$ and rapid clearance was introduced. The drug is not available in all countries and is expensive, so its routine use has been questioned. ${ }^{10,11}$ Comparison has therefore been made between propofol and other induction agents including sodium thiopentone for insertion of Proseal LMA. ${ }^{9}$ These studies showed propofol to be a better agent causing less gagging, coughing and laryngospasm when compared with sodium thiopentone but provided haemodynamic instability. The present study was designed to assess haemodynamic responses obtained with topical lignocaine and sodium thiopentone during Proseal LMA insertion and compared them with propofol administration.

\section{Methods}

After obtaining the approval from Institutional Ethics Committee, one hundred patients of either sex in the age range of 16-60 years belonging to ASAI/II scheduled for open cholycystectomy were selected. Informed consent of every patient was taken. Proseal LMA was used for this study. Patients with gross obesity, severe hypertension, severe diabetes, ischemic heart diseases and history of allergy to thiopentone, lignocaine and propofol were excluded from this study. Patients were randomly allocated to two groups of 50 patients each.

Group-I: Propofol group received injection propofol $1 \%$ in the dose of $2.5 \mathrm{mg} / \mathrm{kg}$ body weight over 30 seconds as an induction agent.

Group-II: Sodium thiopentone group received injection sodium thiopentone (2.5\%) in the dose of $5 \mathrm{mg} / \mathrm{kg}$ body weight over 30 seconds as an induction agent preceded by three minutes four sprays of topical lignocaine $10 \%$. Out of four sprays of lignocaine, two were applied on each side of posterior pharynx.

Preanaesthetic evaluation was done atleast $24 \mathrm{hrs}$ prior to surgery and patients were advised to remain fasting for $12 \mathrm{hrs}$. In the operating room multichannel monitor was attached to the patient and baseline parameters including pulse rate, blood pressure, oxygen saturation and ECG were recorded. All patients received injection fentanyl $1 \mu \mathrm{g} / \mathrm{kg}$ body weight intravenously three minutes before induction. Patients were preoxygenated with $100 \%$ oxygen. Induction of anaesthesia was done with one of the two techniques mentioned above. Appropriate sized Proseal LMA was inserted by one of the anaesthesiolgist who did not know the type of induction technique employed. Blood pressure, pulse rate, oxygen saturation and ECG were recorded at 30 seconds after induction, 1 and 3 minutes after Proseal LMA insertion.

Number of attempts required for successful insertion of pLMA was recorded. Apnoea time was also recorded. Apnoea time is the time interval during which the patient stops breathing and is measured from start of apnoea to start of spontaneous respiration. During this period patient's lungs were not manually ventilated. They received neither volatile anaesthetic agents nor nitrous oxide. Once the patient starts spontaneous respiration, non-depolarizing muscle relaxant was given and anaesthesia was maintained by oxygen and nitrous oxide $(50 \%: 50 \%)$ with vapours of isoflourane. After completion of surgery, neuromuscular block was reversed. Postoperative complications including sore throat were recorded. Statistical analysis was done using student's't' test, Manyt-Whitney test, chi square and odds ratio.

\section{Results}

In our study there were no significant differences among the two groups with respect to age, sex, body weight and ASA status of the patient as shown in Table 1. The mean pulse rate, systolic and diastolic blood pressures are shown in Table 2. The difference in mean pulse rate before induction between the two

\begin{tabular}{lcc}
\hline \multicolumn{3}{l}{ Table 1: Demographic profile in the two groups. (Mean \pm SD) } \\
& Propofol Group & Sodium thiopentone Group \\
\hline Age(years) & $45 \pm 9.5^{*}$ & $43 \pm 9$ \\
Sex(M:F) & $82: 18$ & $80: 20$ \\
Body (Weight) & $54.8 \pm 6.2$ & $53.8 \pm 5.7$ \\
ASA (I: II) & $88: 12$ & $88: 12$ \\
\hline
\end{tabular}

*Mean \pm SD

groups was statistically insignificant, however after induction at $30 \mathrm{~s}, 60 \mathrm{~s}$ and $180 \mathrm{~s}$, it was $75.6 \pm 9.6,69.3 \pm 6.2 \mathrm{and} 68.9 \pm 5.3$ in GI while as it was $81.1 \pm 7.4,76.7 \pm 6.3$ and $74.7 \pm 5.1$ in GII respectively. The Statistical comparison between the two groups

\begin{tabular}{|c|c|c|c|c|c|c|c|c|}
\hline & \multicolumn{4}{|c|}{ Propofol Group } & \multicolumn{4}{|c|}{ Sodium thiopentone Group } \\
\hline & Baseline & $30 \mathrm{~s}$ & $60 \mathrm{~s}$ & $180 \mathrm{~s}$ & Baseline & $30 \mathrm{~s}$ & $60 \mathrm{~s}$ & $180 \mathrm{~s}$ \\
\hline Pulse(bpm) & $86.9^{*} \pm 6.9$ & $75.6 \pm 9.6$ & $69.3 \pm 6.2$ & $68.9 \pm 5.3$ & $85.3 \pm 7.7$ & $81.8 \pm 7.4$ & $76.7 \pm 6.3$ & $74.7 \pm 5.1$ \\
\hline Systolic blood pressure(mmHg) & $126.1 \pm 10.8$ & $104.6 \pm 6.9$ & $99.8 \pm 6.2$ & $105.6 \pm 6.8$ & $123.5 \pm 12.2$ & 116. \pm 18.1 & $113.4 \pm 7.5$ & $118 \pm 7.8$ \\
\hline Diastolic blood pressure $(\mathrm{mmHg})$ & $78.7 \pm 8.2$ & $68.2 \pm 6.3$ & $66.8 \pm 5.8$ & $70.8 \pm 4.0$ & $78.4 \pm 8.0$ & $75.3 \pm 5.0$ & $76 \pm 4.7$ & $77.3 \pm 4.9$ \\
\hline
\end{tabular}

${ }^{*}$ Mean \pm SD 
after induction at $30 \mathrm{~s}, 60 \mathrm{~s}$ and $180 \mathrm{~s}$ was significant $(p<0.05)$.Preinduction systolic blood pressure comparison between the two groups was statistically insignificant. The mean values of systolic blood pressure at 30s, 60s and 180s in GI were 104.6 $\pm 6.9,99.8 \pm 6.2$ and $105.6 \pm 6.8$ while as in GII were 116.1 \pm $8.1,113.4 \pm 7.5$ and $118 \pm 7.8$ respectively. Statistical comparison of systolic blood pressure at 30s, 60s and 180s between the two groups was significant $(p<0.05)$ Preinduction diastolic blood pressure comparison between the two groups was statistically insignificant. The mean values of diastolic blood pressure at $30 \mathrm{~s}$, 60s, 180s in Group I were 68.2 $\pm 6.3,66.8 \pm 5.8$ and $70.8 \pm 4$ while as in Group II were 75.3 $\pm 5.0,76.0 \pm 4.7$ and $77.3 \pm 4.9$ respectively. Statistical comparison of diastolic blood pressure at 30 s, 60s and 180s between the two groups was statistically significant $(p<0.05)$.

The mean duration of apnoea in Group I was 108 \pm 15.1 and in Group II was 74.4 \pm 10.1 as shown in Table 3. These values were statistically compared and the result obtained was significant $(p<0.05)$.In Group I pLMA was inserted in first attempt in $86 \%$ patients and in second attempt in $14 \%$ patients

Table 3: Comparison of different parameters in the two groups

\begin{tabular}{lcc} 
& Group I & Group II \\
Apnoea time(seconds) & $108 \pm 15.1$ & $74 \pm 10.1$ \\
Number of attempts of P LMA insertion 1:2 & $86: 14$ & $86: 14$ \\
Intraoperative course & Uneventful & Uneventful \\
\hline
\end{tabular}

while in Group II pLMA was inserted in first attempt in $86 \%$ and in second attempt in $14 \%$ of patients. These results were statistically compared and found insignificant $(p>0.05)$. Intratraoperative course of all patients remained uneventful. Oxygen saturation $\left(\mathrm{SpO}_{2}\right)$ between the two groups remained 99$100 \%$ and difference between two groups was statistically insignificant. All patients completed the study. In the postoperative period patients remained without complications except some patients developed sore throat which was statistically insignificant between two groups $(p>0.05)$.

\section{Discussion}

Insertion of Proseal LMA needs abolition of airway reflexes and pressure responses. This is most commonly achieved by using propofol as an induction agent. But this drug is costlier one and is not available in all countries. These things make one to assess and think for an alternative induction agent. Many induction agents have been used for this purpose. Propofol provided satisfactory conditions for pLMA insertion as compared to other agents but caused haemodynamic instability. ${ }^{9,12}$ The reason being that propofol suppresses airway reflexes and pressure responses more effectively as compared to sodium thiopentone. This study was done to assess the haemodynamics responses obtained with use of topical lignocaine prior to sodium thiopentone administration during
Proseal LMA insertion and were compared with those obtained with propofol administration.

Demographic factors like age, weight, sex and age distributions were more or less same and statistically insignificant between the two groups. Initially heart rate remained normal due to adequate premedication by fentanyl. Insertion of Proseal LMA causes pressure responses due to sympathetic stimulation. Propofol induction caused decrease in heart rate, systolic and diastolic pressures while pLMA insertion and resulted in haemodynamic instability. Topical lignocaine was used in this study prior to sodium thiopentone induction to abolish airway reflexes and haemodynamic responses, which resulted in better haemodynamic stability while pLMA insertion. In our study, decline in heart rate, systolic and diastolic blood pressures occurred more in propofol group at 30, 60 and 180 seconds after Proseal LMA insertion than in topical lignocaine and sodium thiopentone. S. Carlier and Van $\mathrm{Akin}^{13}$ in 1989 found a decrease in heart rate after propofol administration. C.R. Seavell et al ${ }^{8} 1996$, G.C. Cumingset al ${ }^{14} 1984$ and S. Carlier et al ${ }^{13} 1989$ found a greater fall in systolic as well as diastolic blood pressures in Propofol group than in Thiopentone group. Our study also showed the same results. Thus topical lignocaine and sodium thiopentone provided better haemodynamic stability during Proseal LMA insertion than Propofol.

Duration of apnoea was more in propofol Group (108 sec) as compared to Thiopentone Group (74 sec) and difference between two groups was statistically significant. CR Seavell et al ${ }^{8}$ found a mean duration of apnoea of $103 \mathrm{sec}$ in propofol group as compared to $65.4 \mathrm{sec}$ in thiopentone group. Propofol is a potent respiratory depressant. Proseal LMA was inserted in both groups in the first attempt in most of patients. Seven patients out of 50 in each group needed second attempt for successful insertion of pLMA. C.R. Seavel ${ }^{18}$ found that LMA was inserted in first attempt in all patients successfully. Only five out of 44 in propofol group and four out of 46 in Thiopentone group needed second attempt for insertion of pLMA. No patient had a fall in oxygen saturation while inserting pLMA. No patient developed complication intraoperatively and postoperatively over a period of 12 hours except sore throat which was found in equal numbers in both groups and was found to be statistically insignificant.

We conclude that topical lignocaine and sodium thiopentone provides better haemodynamic stability while Proseal LMA insertion than propofol but duration of apnoea was more in propofol group.

\section{References}

1. Giriesh P Joshi, Yoshmi Inagaki, Paul F White, et al. Use of laryngeal mask airway as an alternative to the tracheal tube during ambulatory anaesthesia.AnaesthesiaAnalgesia 1997; 85:573-7.

2. Brain AIJ, Mcghee TD, Thomas A, Abusaad MAW, Bushmal JA. The Laryngeal MaskAirway-Development and Preliminary trials of a new type airway. Anaesthesia 1985;40:356-361.

3. Brain AIJ. The Laryngeal Mask- a new concept in airway management. BrJAnaesthesia1983;55:801-805. 
4. Joseph A Fisher, Chodambaram Ananthnarayn Gerald Edelist. Role of the laryngeal mask airway management. Canadian Journal Anaesthesia 1992;39(1):1-3.

5. Pramood P Bapat and Chandy Verghese. Laryngeal Mask Airway and the incidence of regurgitation during gynaecological laproscopies. Anaesth Analg 1997;85:139-43.

6. Ian Smith, Paul F White. Use of Laryngeal Mask Airway as an alternative to a facemask during out patient Arthroscopy. Anaesthesiology 1992;77:850-855.

7. Bimla Sharma, Baily PM. LMA in present day anaesthesia. Journal of Anesthesiology Clinic Pharmacology 2007;23(1):5-15.

8. Seavell CR, Cook TM. Topical lignocaine and sodium thiopentone for the insertion of LMA, a comparison with propofol.Anaesthesia 1996;51:699-701.

9. Patrick Scanlon, Michael Carey, Micheal Power. Patient response to Laryngeal MaskAirway insertion after induction with Propofol or Thiopentone. Canadian Journal Anaesthesia 1993;40(9):816-8.

10. PeacockJE, Lewis RP, Reilly CS, Nimmo WC. Effect of different rates of infusion of propofol for induction of induction of anaesthesia in elderly patients. BrJ Anaesthesia 1990;65:346-352.

11. Brimacombe, Berry A. Insertion of LMA - an indication for propofol.Anaesthesia1992;20(3):19.

12. Brown JW, Patel, Ellis FR. Comparison of propofol and sodium thiopentone for Laryngeal Mask Airway insertion. European Jour Anaesthesiology 1986;3:11-14.

13. Carlier S, Van Aken H, and Vandermeersch E. Does nitrous oxide affect the haemodynamic effects of anaesthesia induction with propofol? Anaesthesia Analg 1989;68:728-3.

14. Cummings GC, DixonJ, Kay NH, Windsore JPW, MMorgen. Does requirements of ICI35868 (propofol diprivan) in a new formulation for induction of anaesthesia. Anaesthesia 1984;39: 1168-16. 